\title{
Costs and outcomes in a regional neonatal intensive care unit
}

\author{
B NEWNS, M F DRUMMOND, G M DURBIN, AND P CULLEY \\ Health Services Management Centre, University of Birmingham, and Birmingham Maternity Hospital
}

SUMmaRY At the Birmingham Maternity Hospital the mean cost of caring for surviving infants who require neonatal intensive care ranges from approximately $£ 2500$ (for infants above $1500 \mathrm{~g}$ birthweight), to $£ 5500$ (for infants 1000 to $1499 \mathrm{~g}$ birthweight), to $£ 10000$ (for infants less than $1000 \mathrm{~g}$ birthweight). The mean cost of caring for non-survivors is $£ 1000$ or less, with little difference between the birthweight groups. These figures are based on the lengths of stay in three treatment regimens-intensive care, high dependency care, and special care - the average daily costs of which are estimated to be $£ 235, £ 122$, and $£ 43$ respectively. The survival of very low birthweight infants (less than $1500 \mathrm{~g}$ ) at this hospital has improved from $42 \%$ to $73 \%$ since the introduction of regional funding for neonatal intensive care. This increase in survival has been brought about without undue disability in the survivors.

It is generally accepted that investment in neonatal intensive care reduces mortality among very low birthweight infants. Opponents would argue, however, that in the light of competing demands for scarce resources, the costs of the services are high, especially if morbidity is not reduced. Although outcome in terms of mortality and morbidity are well documented in this country ${ }^{1}$ and both costs and outcomes have been investigated elsewhere ${ }^{2}$ data on costs of neonatal intensive care are particularly lacking in the United Kingdom. ${ }^{3}$ This study attempts to remedy this omission and at the same time to investigate whether investment (in this particular regional referral unit) has been matched by a significant improvement in outcome.

The evaluation has been carried out at the neonatal unit at Birmingham Maternity Hospital. The hospital delivers 5000 infants per annum out of approximately 70000 births in the West Midlands. The neonatal unit was designated a regional referral centre at the beginning of 1979, when six of the existing 36 special care cots were upgraded to provide three intensive care plus three high dependency care cots. The unit accepts inborn infants from the Birmingham Maternity Hospital (which includes in utero transfers from other hospitals within the region) and also operates a 'flying squad' service for sick outborn infants. During a two year period (1980 and 1981) a total of 1329 infants were admitted to the unit, of which 137 survivors and 53 non-survivors required intensive care, 189 survivors and 22 non-survivors required high dependency care, and 928 survivors required special care only.

The criteria for admitting infants to these different treatment regimens are as follows:

Intensive care. Those infants requiring positive pressure mechanical ventilation or total parenteral nutrition, and initially all those infants with birthweights of less than $1000 \mathrm{~g}$.

High dependency care. Those infants requiring constant positive airway pressure, continuous monitoring of vital functions, oxygen therapy, intravenous therapy, and initially, those infants with birthweights of less than $1500 \mathrm{~g}$.

Special care. Those infants who have required intensive care and high dependency care, but now require skilled nursing supervision of temperature regulation, feeding, and simple treatments, and those infants admitted only for this form of care.

\section{Methods}

The number of days the 1329 babies admitted spent in the three phases of care was analysed by three birthweight groups (less than $1000 \mathrm{~g}, 1000$ to $1499 \mathrm{~g}$, and $1500 \mathrm{~g}$ and above), for inborn and outborn infants, survivors and non-survivors.

The costs attributable to the neonatal unit were categorised into three main groups, direct patient 
care (nurse staffing, medical staffing, and neonatal equipment), support services (pathology departments, radiology, pharmacy, and medical and surgical supplies), and hospital overheads (administration and medical records, domestic staff, laundry, staff catering, and general services). The study concentrates on the current costs of providing care at this hospital. Those wishing to relate our data to their own situation would need also to consider any capital costs in upgrading or extending their accommodation to house a neonatal intensive care unit.

For each of these items an estimate of the cost of an average patient day for the three treatment regimes was derived by using: (a) detailed observation of clinical and nursing procedures in assessing nursing and medical time. (Staff to cot ratios were available for nurse staffing but these did not reflect actual nursing time spent because staff moved between the different sections of the unit according to where they were needed; (b) investigation of medical case notes (backed up by observation and discussion with nursing and technical personnel) to determine the use of neonatal equipment. (Maintenance charges were allocated in the same proportion as equipment; (c) investigation of medical case notes to determine the number of pathology tests, radiographs, and pharmacy prescribed items; (d) detailed observation of clinical procedures in assessing the use of medical and surgical supplies (mostly disposable items); (e) simple equal apportionment by inpatient day for hospital overheads. (Further details of the costing methodology are available from the authors.)

\section{Results}

Lengths of stay of infants requiring neonatal intensive care. From Table 1 it can be seen that the length of stay in the more intensive forms of care increases as birthweight falls. Median days stay are less than the mean because a small number of very ill infants
Table 2 Categories of cost

\begin{tabular}{lc}
\hline Category & $\begin{array}{c}\text { Proportion of itemised } \\
\text { cost to total cost (\%) }\end{array}$ \\
\hline Direct patient care & \\
Nurse staffing & 47 \\
Medical staffing & 9 \\
Equipment and maintenance & 7 \\
Support services & \\
Pathology & \\
Clinical Chemistry & 7 \\
Histopathology & 3 \\
Bacteriology & 2 \\
Haematology & 2 \\
Unallocated pathology & 1 \\
Medical and surgical supplies & 5 \\
Pharmaceutical services & 3 \\
Radiology & 2 \\
Hospital overheads & 12 \\
Total & 100 \\
\hline
\end{tabular}

remain in the unit for longer periods. For inborn infants above $1500 \mathrm{~g}$ the mean number of intensive care plus high dependency care days is 11 , for infants 1000 to $1499 \mathrm{~g}$ it is 33 days, and for infants less than $1000 \mathrm{~g}$ it is 61 days. The longer duration of intensive care required by the outborn infants with birthweights less than $1500 \mathrm{~g}$ was not statistically significant (applying a two tailed Student's $t$ test, 1\% significance level). The median length of stay in intensive care for non-survivors, at two days. (mean $3 \cdot 5$, range 0 to 24 ) showed little difference between the birthweight groups.

Costs. The total costs attributable to the neonatal unit were estimated to be $£ 620000$ for 1980 (November 1980 pay and prices). Eighty six per cent of costs remained the same in real terms over the two years, representing mostly staff costs, together with overheads and equipment costs. Medical and surgical consumable supplies represented the only real change in costs from 1980 to 1981 in line with an increase in patient days. From Table 2 it can be seen that direct patient care represented $63 \%$ of total

Table 1 Lengths of stay of survivors of neonatal intensive care for the period 1980 to 1981

\begin{tabular}{|c|c|c|c|c|c|c|c|c|c|c|}
\hline \multirow[t]{2}{*}{$\begin{array}{l}\text { Birthweight } \\
\text { (g) }\end{array}$} & \multirow[t]{2}{*}{$\begin{array}{l}\text { No } \\
\text { infants }\end{array}$} & \multicolumn{3}{|c|}{$\begin{array}{l}\text { Days spent in } \\
\text { intensive care }\end{array}$} & \multicolumn{3}{|c|}{$\begin{array}{l}\text { Days spent in } \\
\text { high dependency care }\end{array}$} & \multicolumn{3}{|c|}{$\begin{array}{l}\text { Days spent in } \\
\text { special care }\end{array}$} \\
\hline & & Median & Mean & Range & Median & Mean & Range & Median & Mean & Range \\
\hline $\begin{array}{l}\text { Less than } 100 \\
\text { Inborn } \\
\text { Outborn }\end{array}$ & $\begin{array}{r}15 \\
6\end{array}$ & $\begin{array}{r}9 \\
15\end{array}$ & $\begin{array}{l}(14) \\
(19)\end{array}$ & $\begin{array}{l}1-53 \\
3-57\end{array}$ & $\begin{array}{l}43 \\
45\end{array}$ & $\begin{array}{l}(47) \\
(44)\end{array}$ & $\begin{array}{l}25-80 \\
27-59\end{array}$ & $\begin{array}{r}24 \\
1\end{array}$ & $\begin{array}{r}(23) \\
(7)\end{array}$ & $\begin{array}{l}0-37 \\
0-28\end{array}$ \\
\hline $\begin{array}{l}1000-1499 \\
\text { Inborn } \\
\text { Outborn }\end{array}$ & $\begin{array}{r}44 \\
7\end{array}$ & $\begin{array}{l}3 \\
9\end{array}$ & $\begin{array}{r}\text { (5) } \\
\text { (11) }\end{array}$ & $\begin{array}{l}1-28 \\
2-27\end{array}$ & $\begin{array}{l}24 \\
23\end{array}$ & $\begin{array}{l}(28) \\
(25)\end{array}$ & $\begin{array}{r}3-70 \\
12-51\end{array}$ & $\begin{array}{r}18 \\
3\end{array}$ & $\begin{array}{r}(22) \\
(9)\end{array}$ & $\begin{array}{l}0-60 \\
0-52\end{array}$ \\
\hline $\begin{array}{l}1500 \text { and } a b o \\
\text { Inborn } \\
\text { Outborn }\end{array}$ & $\begin{array}{l}51 \\
14\end{array}$ & $\begin{array}{l}3 \\
3\end{array}$ & $\begin{array}{l}\text { (4) } \\
\text { (3) }\end{array}$ & $\begin{array}{l}1-16 \\
1-11\end{array}$ & $\begin{array}{l}6 \\
6\end{array}$ & $\begin{array}{l}\text { (7) } \\
\text { (8) }\end{array}$ & $\begin{array}{l}0-30 \\
0-34\end{array}$ & $\begin{array}{r}17 \\
4\end{array}$ & $\begin{array}{r}(17) \\
(3)\end{array}$ & $\begin{array}{l}0-62 \\
0-10\end{array}$ \\
\hline
\end{tabular}

Mean stay for outborn infants is lower than for inborn infants primarily because the former are transferred to referring hospitals before discharge. 
Table 3 Cost of a period of neonatal care by birthweight group

\begin{tabular}{|c|c|c|c|c|c|c|}
\hline \multirow[t]{3}{*}{ Birthweight $(g)$} & \multicolumn{6}{|c|}{ Combined cost of intensive, high dependency, and special care $£^{*}$} \\
\hline & \multicolumn{3}{|l|}{ Inborn } & \multicolumn{3}{|c|}{ Outborn } \\
\hline & Mean & Median & Range & Mean & Median & Range \\
\hline \multicolumn{7}{|l|}{ Survivors } \\
\hline Less than 1000 & 10000 & 9500 & $4900-18200$ & 10100 & 8900 & $6800-19100$ \\
\hline $1000-1499$ & 5500 & 5300 & $1300-12800$ & 6000 & 5700 & $2000-8500$ \\
\hline 1500 and above & 2500 & 2300 & $500-8900$ & 1800 & 1200 & $700-5500$ \\
\hline Non-Survivors & 800 & 500 & $200-3300$ & 1000 & 800 & $200-5600$ \\
\hline
\end{tabular}

To nearest $£ 100$ (at November 1980 pay and prices)

costs, support services accounted for $25 \%$, and overheads the remaining $12 \%$. Average daily costs for the three phases of care were estimated to be $£ 235$ for intensive care, $£ 122$ for high dependency care and $£ 43$ for special care. In Table 3 the mean, median, and range of the combined cost (to the nearest $£ 100$ ) for each surviving infant requiring neonatal intensive care has been calculated from their length of stay in the three categories of care times average daily cost for each of these levels. The mean cost of caring for non-survivors is $£ 1000$ or less, with little difference between the birthweight groups.

\section{Discussion}

Neonatal intensive care is considered to be one way of reducing perinatal and neonatal mortality. Our findings indicate the costs associated with the current provision of neonatal intensive care in a major English maternity hospital, with costs of providing intensive care to inborn infants ranging from $£ 2500$ (for infants above $1500 \mathrm{~g}$ birthweight) to $£ 10000$ (for infants under $1000 \mathrm{~g}$ ). The prevention of low birthweight might be a more cost effective alternative, but the ways of achieving this still need to be investigated.
It can be seen from Table 4 that although the survival for all birthweight groups improved after the introduction of neonatal intensive care the change is most noticeable in infants of very low birthweights (less than $1500 \mathrm{~g}$ ). For the birthweight group 1000 to $1499 \mathrm{~g}$ the improvement in survival was from $63 \%$ to $83 \%$ and for the infants weighing less than $1000 \mathrm{~g}$ the improvement was from $11 \%$ to $47 \%$ over the same time periods.

Sinclair $e t a l^{4}$ have pointed to the dangers of assessments of outcome based solely on regional referral units, owing to the possibility of selection bias. That is, when a referral centre is established it may attract those babies (or pregnancies) with the best prognosis from the surrounding district. Therefore, improvements in survival observed in the referral centre may be partly offset by reductions in survival elsewhere.

The empirical impact of selection bias is likely to vary from place to place, depending on local referral patterns. Sinclair et al estimated that selection bias accounted for $28 \%$ of the improvement in the survival rate among all very low birthweight babies born in a region of Ontario during the two periods they studied. To investigate this possibility in the West Midlands we have also extracted data for the region as a whole, excluding infants born at this

Table 4 Very low birthweight neonatal survival (1976-78 and 1979-81) in the West Midlands (excluding infants born in Birmingham Maternity Hospital (BMH)) compared with infants born in BMH before and after regional funding for neonatal intensive care

\begin{tabular}{|c|c|c|c|c|c|c|}
\hline \multirow{2}{*}{$\begin{array}{l}\text { Birthweight } \\
(\mathrm{g})\end{array}$} & \multicolumn{3}{|c|}{ West Midlands (excluding $B M H$ ) } & \multicolumn{3}{|l|}{$B M H$} \\
\hline & Live births & Neonatal deaths & $\%$ survival & Live births & Neonatal deaths & $\%$ survival \\
\hline \multicolumn{7}{|l|}{$1976-1978$} \\
\hline Less than 1000 & 466 & 379 & 19 & 44 & 39 & 11 \\
\hline $1000-1499$ & 918 & 348 & 62 & 64 & 24 & 63 \\
\hline Less than 1500 & 1384 & 727 & 47 & 108 & 63 & 42 \\
\hline \multicolumn{7}{|l|}{ 1979-1981 } \\
\hline $1000-1499$ & 1039 & 299 & 71 & 126 & 22 & 83 \\
\hline Less than 1500 & 1550 & 672 & 57 & 172 & 46 & 73 \\
\hline
\end{tabular}


hospital. We find that the survival of infants with a birthweight less than $1500 \mathrm{~g}$ born in other units also showed an improvement, from $47 \%$ in $1976-78$ to $57 \%$ in $1979-81$ (the three years before and after funding of the regional neonatal unit). In all categories the figures for the rest of the region show an improvement in survival, although the increase has been greater in the regional unit. The greater increase in survival, however, is not explained by the better prognosis of in utero transfers, of which there were 41 in 1979-81. The survival of these babies was $71 \%$ (for birthweight less than $1500 \mathrm{~g}$ ); that is, similar to that of all very low birthweight infants cared for in the unit.

Another important aspect of the outcome of neonatal intensive care is the longer term mortality and morbidity of babies discharged from hospital, which can have cost implications. Forty-six of the 172 infants born with a birthweight of less than $1500 \mathrm{~g}$ in 1979-81 died in the neonatal period and a further five died before the age of 1 year. The survivors have now been followed up by consultant paediatricians, and routine clinical examination and developmental assessment has been undertaken. Four of the 121 surviving infants were not seen by paediatricians ('lost to follow up'); two moved and two failed to attend the clinic but have now been seen by the local health visitor and are said to be developing normally. Seven had serious disability (two with severe spastic quadraplegia, one with mild spastic quadraplegia, and two with mild spastic diplegia, one with a right hemiplegia, and one with convulsions and delayed speech). The remainder are developing normally ('healthy'). (See the Figure.) The extra cost of this morbidity is very dependent on the nature of the disability and with our very small numbers of handicapped babies a detailed costing was not undertaken.

Over the two year study period a total of eight infants were admitted to the neonatal unit with a birthweight of less than $750 \mathrm{~g}$. Only two survived. With further improvements in care more of these infants are expected to survive in the future,

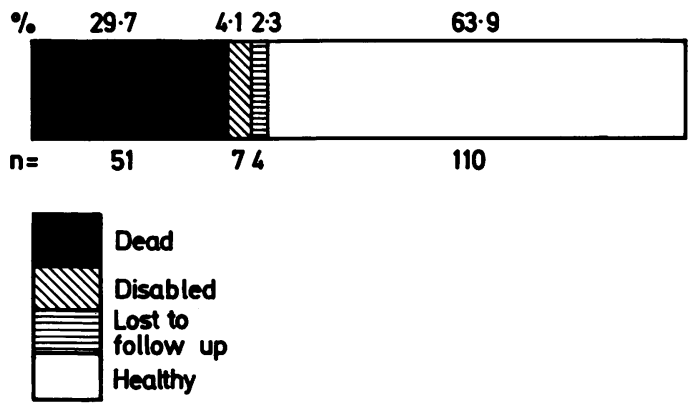

Figure Outcome for inborn infants of birthweight less than $1500 \mathrm{~g}, 1979-81$.

although possibly at a greater financial cost. Furthermore, hospitals with higher rates of disability in their survivors will have considerably higher costs in providing care.

We thank Doctors Insley, Wharton, and Hughes for follow up data; the nursing staff at the Neonatal Unit and the Medical Records Department (Birmingham Maternity Hospital) for their cooperation and support; David Chevins (Senior Assistant District Treasurer) for assistance with financial data; the Regional Statistical Information Department; and Dr Dorothy Kyle (Specialist in Community Medicine) for commenting on an earlier draft. BN was in receipt of a Studentship from SSRC.

\section{References}

${ }^{1}$ Stewart AL, Reynolds EOR, Lipscombe AP. Outcome for infants of very low birthweight: survey of world literature. Lancet $1981 ; \mathbf{i}: 1038-40$.

${ }^{2}$ Boyle MH, Torrance GW, Sinclair JC, Horwood SP. Economic evaluation of neonatal intensive care of very-low-birth-weight infants. N Engl J Med 1983;308:1330-7.

${ }^{3}$ House of Commons Select Committee on the Social Services. Second report, session 1979-80. Perinatal and neonatal mortality. Vol 1. London: HMSO, 1980.

${ }^{4}$ Sinclair JC, Torrance GW, Boyle MH, Horwood SP, Saigal S. Evaluating neonatal intensive care (letter). Lancet 1981;ii:1052.

Correspondence to Dr G M Durbin, Birmingham Maternity Hospital, Queen Elizabeth Medical Centre, Birmingham B15 2TG.

Received 23 July 1984 